\title{
Public Health Citizen Science; Perceived Impacts on Citizen Scientists: A Case Study in a Low-Income Neighbourhood in the Netherlands
}

\author{
Lea Den Broeder*,", Lidwien Lemmens*, Serfanim Uysal' ${ }^{\dagger}, K^{*}$ arin Kauw ${ }^{\dagger}$, Jitske \\ Weekenborg ${ }^{\ddagger}$, Michaela Schönenberger§, Simone Klooster-Kwakkelstein", Mieke \\ Schoenmakers", Willie Scharwächter**, Annemarije Van de Weerdll, Samira El Baouchi*, \\ Albertine Jantine Schuit ${ }^{*}$ and Annemarie Wagemakers ${ }^{\dagger \dagger}$
}

Citizen science - the active participation of lay people in research - may yield crucial local knowledge and increase research capacity. Recently, there is growing interest to understand benefits for citizen scientists themselves. We studied the perceived impacts of participation in a public health citizen science project on citizen scientists in a disadvantaged neighbourhood in the Netherlands. Local citizen scientists, characterised by low income and low educational level - many of whom were of migrant origin - were trained to interview fellow residents about health-enhancing and health-damaging neighbourhood features. Experiences of these citizen scientists were collected through focus groups and interviews and analysed using a theoretical model of potential citizen science benefits. The results show that the citizen scientists perceived participation in the project as a positive experience. They acquired a broader understanding of health and its determinants and knowledge about healthy lifestyles, and took action to change their own health behaviour. They reported improved self confidence and social skills, and expanded their network across cultural boundaries. Health was perceived as a topic that helped people with different backgrounds to relate to one another. The project also induced joint action to improve the neighbourhood's health. We conclude that citizen science benefits participants with low educational or literacy level. Moreover, it seems to be a promising approach that can help promote health in underprivileged communities by strengthening personal skills and social capital. However, embedding projects in broader health promotion strategies and long-term engagement of citizen scientists should be pursued to accomplish this.

Keywords: public health; community; disadvantaged groups; residents; citizen science experiences; neighbourhood

\section{Introduction}

Citizen science - the active participation of lay people in scientific research in ways other than as serving as research objects or respondents - has important advantages for science. It adds knowledge and insights that may help solve complex problems (Fischer 2000) and it may reduce the work load for researchers in

\footnotetext{
* National Institute for Public Health and the Environment, NL

${ }^{\dagger}$ Eigenwijks, NL

₹ Bijzonder Wonen, NL

$\S$ Municipal Health Authority Amsterdam, NL

" Amsterdam University of Applied Sciences, NL

" De Zoete Appel, NL

** Scharwächter leefstijlspecialist, NL

${ }^{+t}$ Wageningen University and Research Centre Health and Society, NL
}

Corresponding author: Lea Den Broeder (lea.den.broeder@rivm.nl) labour-intensive projects, for example, by gathering large amounts of data or collecting data that are otherwise difficult to obtain owing to factors such as geographic spread or hard-to-reach populations (Gommerman and Monroe 2012). The citizen science approach also yields benefits for its participants, for example, by enhancing scientific literacy or public knowledge about specific topics (Bonney et al. 2009, Brossard et al. 2005, Cronje et al. 2011, Den Broeder et al. 2016)

One of the fields in which the impacts of citizen science could be particularly important is public health and the promotion of health research. Community participation is strongly advocated in health promotion, for example, the Ottawa Charter on health promotion emphasises "strengthening community action" as one of its core strands of action (World Health Organization 1986). Partnerships among researchers and community members are considered to be important opportunities for 
empowering communities to take action for better health (Minkler 2000, Israel et al. 1998, Brown 1997, South and Phillips 2014, Wagemakers et al. 2008, Wagemakers et al. 2010, Horowitz et al. 2009).

In practice, the knowledge base for health promotion strategies is often limited to expert-driven knowledge and an epidemiological paradigm (Vaandrager et al. 2011, Minkler et al. 2003). In Amsterdam, the Netherlands, local policy makers aimed to change that by setting up a citizen science project to develop a "bottom-up" health policy for a disadvantaged neighbourhood. The project's main goal was to yield important grassroots information on views, needs, and concerns of the community that could assist in designing a more inclusive policy for this so-called "priority" neighbourhood. Through this project, community members served as peer interviewers of their fellow residents providing important contextual and "insider" information helpful in analysing project data. The project may therefore be classified as a collaborative project in the classification of Shirk et al. (2012). In the process, the project team ensured that the project also benefited the participating citizen scientists by enhancing their understanding of the broader determinants of health and their personal competencies. Because the project was intended to provide new opportunities and possibilities for residents to become actively engaged in improving the community's health, assessing project impacts on its citizen scientist participants was a core element of the project's design.

This paper aims to contribute to knowledge about the impacts of participation on citizen scientists in the field of public health, with a focus on disadvantaged groups. Our main research question was: What impacts were experienced by citizen scientists participating in a public health research project?

\section{Methods \\ Project setting}

The project took place in 2014-2015 in Slotermeer, a disadvantaged neighbourhood in Amsterdam, the Netherlands. A project team led by "Eigenwijks," a local community work organisation that represents, supports, and activates Slotermeer residents, was formed to set up the project. The evaluation of project impacts on its citizen scientist participants was carried out by researchers who served on the project team.

Slotermeer faces many health and community issues including obesity, mental health, loneliness, poverty, and a poor liveability. More than $60 \%$ of the population is of non-western migrant origin (Gemeente Amsterdam 2015a). Residents are considered as "hard to reach" for local public health policy makers, and this project was initiated by the local District Council. Although originally planned for 2014 it was extended to 2015 owing to the enthusiasm of the District Council about its results. Therefore, one group of citizen scientists was enrolled in 2014 and a second group in 2015.

The project objective was to gather information about resident views concerning potential neighbourhood health assets as a basis for determining local policy. Participants in the project were named "Health Ambassadors," but we will refer to them here as "citizen scientists." The stages of the project were training of citizen scientists, data collection by citizen scientists, and reporting and analysis of results.

\section{Citizen scientist training}

Participants were trained in groups of five to eight through an "experiential learning" approach with a focus on learning processes rather than on attaining fixed end points (Kolb 1984). The citizen scientists were stimulated to link their personal day-to-day experiences to the training content, thus creating new knowledge that combines both. Training was developed and carried out incrementally (MS, WS) with support and input from the project group (SU, KK, SKK, MS, LDB) as well as from the participants. For example, the participants asked for extra help to organise interviews. Therefore, an additional meeting was organised as a kick-off to the interview stage, and a printed guideline about how to organise interviews was developed and provided.

Training addressed three main topics. First, the perspective on health as "the ability to adapt and selfmanage in the face of social, physical, and emotional challenges" (Huber et al. 2011) was explained. Second, techniques to recruit interviewees and to carry out group interviews based on "motivational interviewing" (Miller and Rollnick 2007) were described. Third, to enhance the citizen scientists' understanding of the broadness of factors that may impact community health, a Dutch translation of the model of sustainable neighbourhoods developed by Egan (2004) was explained and discussed.

Training took place over three half-day sessions within a six-week time span. The training sessions were evaluated by a questionnaire focusing on satisfaction level of the citizen scientists with the training in general, both as a preparation for the research work and as a process. It also contained open-ended questions asking about further needs. The overall satisfaction level with the training was 8.2 on a 10-point scale for 2014 and 8.0 for 2015. Several citizen scientists from the 2014 group suggested better matching of participants with different educational or language levels in different groups. This was implemented in 2015; citizen scientists then rated the training level as well-matched to their needs and knowledge level.

A schematic overview of the training is provided in Table 1.

\section{Data collection by citizen scientists}

Citizen scientists collected data during a six-week period launched byakick-offdinner thatcelebrated thefinalisation of the training and provided instructions and printed guideline to help participants set up interviews. Interview topics included what aspects of the neighbourhood residents viewed as health enhancing (health assets) and what aspects needed to be improved (barriers for health). The citizen scientists also asked residents which actions the residents themselves could develop to improve the community's health. The citizen scientists were trained to carry out group interviews but were invited to also use 
Table 1: Training overview.

\begin{tabular}{|c|c|c|c|}
\hline Session & Topics & Methods & Materials \\
\hline \multirow[t]{3}{*}{ Training day 1} & $\begin{array}{l}\text { Introduction of group members and } \\
\text { trainers to one another }\end{array}$ & \multirow[t]{3}{*}{$\begin{array}{l}\text { Group discussion, storytelling, } \\
\text { mini lectures }\end{array}$} & \multirow[t]{3}{*}{ Flip chart } \\
\hline & Introduction to the project & & \\
\hline & $\begin{array}{l}\text { Health definitions (including } \\
\text { "Positive Health") }\end{array}$ & & \\
\hline Training day 2 & Interview techniques and attitudes & $\begin{array}{l}\text { Group discussion, small group } \\
\text { assignments, video, mini lectures }\end{array}$ & $\begin{array}{l}\text { Powerpoint slides, video examples } \\
\text { of interview techniques, flip chart, } \\
\text { fill-in forms to reflect on video }\end{array}$ \\
\hline \multirow[t]{3}{*}{ Training day 3} & Interview techniques and attitudes & \multirow{3}{*}{$\begin{array}{l}\text { Group discussion, video, mini } \\
\text { lectures }\end{array}$} & \multirow{3}{*}{$\begin{array}{l}\text { Powerpoint slides, video examples } \\
\text { of interview techniques, flip chart }\end{array}$} \\
\hline & $\begin{array}{l}\text { Health determinants (including } \\
\text { Egan model) }\end{array}$ & & \\
\hline & Next steps in project & & \\
\hline \multirow[t]{3}{*}{ Kick-off meeting } & Recruitment of interviewees & \multirow[t]{3}{*}{ Joint dinner, group instruction } & \multirow{3}{*}{$\begin{array}{l}\text { Handout with tips for planning of } \\
\text { interviews } \\
\text { Reporting form "My Group's Story" }\end{array}$} \\
\hline & Reporting & & \\
\hline & Next steps & & \\
\hline
\end{tabular}

other methods, such as one-on-one interviews, if they preferred. Indeed, the citizen scientists used a large variety of interview methods, in varied settings, and with many types of interviewees. Interviews took place in homes, schools, shops, community meeting places, and in the street. Some citizen scientists interviewed family and friends, others interviewed random people, and others purposefully searched for different "voices," for example, by interviewing youngsters or older people. According to the citizen scientists, these groups were often not listened to by neighbourhood health professionals. Citizen scientists received practical support from neighbourhood community workers assisted by students from the Amsterdam University of Applied Sciences (SU, KK, JW, and SKK). Support included developing personal strategies to engage residents in interviews. The citizen scientists recorded the results of their interviews on easyto-fill out forms and interviewed a total of 316 fellow residents; one trained citizen scientist did not manage to carry out interviews owing to personal circumstances but remained a group member in all other project stages.

\section{Data reporting and analysis by citizen scientists}

The third project stage, reporting of results and analysis, consisted of discussion of the interview results in focus groups and jointly interpreting and explaining the data collected, after which these data were further analysed (LdB) yielding an overview of health enhancing neighbourhood features as well as barriers brought forward by the residents interviewed (Table 2). Results were presented back to the citizen scientists, to the community, and to the District Council in a report and two brochures (den Broeder et al. 2015, RIVM 2015, RIVM 2016). Moreover, a meeting with all citizen scientists was organised in which these end results were discussed, with the aim of developing recommendations for action, to be taken either by the District Council, by professionals in the neighbourhood, or by residents themselves.

After their interview activities, both the 2014 and 2015 citizen scientist groups organised a neighbourhood health festival in the community centre, supported by community workers (KK, SU, and JW). At the festival each citizen scientist received a "Health Ambassador" certificate confirming their participation in the project. Project results were used as input for the District Council's District Development Strategy. For example, citizen scientists have become actively engaged in the development of a new programme to combat loneliness in the neighbourhood, one of the topics they discussed during the analysis stage. Moreover, the citizen scientists are explicitly mentioned in the District Development Plans for 2016 and 2017, and the intention is that a larger network of "ambassadors for health" will be developed for the other neighbourhoods in the larger Nieuw-West area (Gemeente Amsterdam 2015b, Gemeente Amsterdam 2016).

\section{Research study design}

To study the project impacts on the citizen science participants we applied an action research approach; activities with and by citizen scientists were closely linked to research activities carried out to evaluate the perceived impacts of the project. For example, focus groups with the citizen scientists were organised to collect data about how they perceived impacts of the project, but also for them to share and discuss the results of their interviews with each other. Mixed methods were applied as a concurrent triangulation strategy (Creswell 2009). An overview of the project after the initial recruitment, for the citizen scientists enrolled in both 2014 and 2015, is provided in Figure 1.

Selection of citizen scientists to study

All citizen scientists who remained engaged throughout the project were included in this study. They had been selected by the local community work organization, using its resident network in the neighbourhood. They were invited in an informal way, by phone, in person, or in groups gathered at the community center (SU, KK). Several additional persons, having heard about the project from friends in the neighbourhood, came forward without 
Table 2: Neighbourhood features brought forward by residents $(\mathrm{N}=316)$ in the interviews carried out by the citizen scientists.

\section{Health enhancing neighbourhood features}

Attractive and abundant public greenery, in particular the Sloterplas lake

Further enhancement options: Public toilets, more and safer well-kept children's playgrounds; free or inexpensive public sports facilities for adults

Transport and connectivity is rated good. Public transport is rated as excellent

Further enhancement option: Improve traffic safety around schools

Social and health facilities are abundant and good quality Further enhancement option: Better communication to provide residents with information about the availability of these services

\section{Barriers for health in the neighbourhood}

Insufficient information about healthy lifestyles, insufficient health promotion activities

One-sided local economy with a small variety of shops; abundance of unhealthy food choices and junk food stores Unhealthy behaviour of people in the streets, in particular junk food and soft drink consumption

Poverty as such is a health threat; moreover it is a barrier for people to adopt healthy life styles

Poor social cohesion and lack of intercultural exchange, loneliness and a sense of unsafety; lack of meeting places for social contact

Litter in public space, lack of litter disposal facilities and resulting pests inadequate environmental behaviour of residents

Poor quality housing, unhealthy indoor environment and dwellings that are too small for the size of families living there

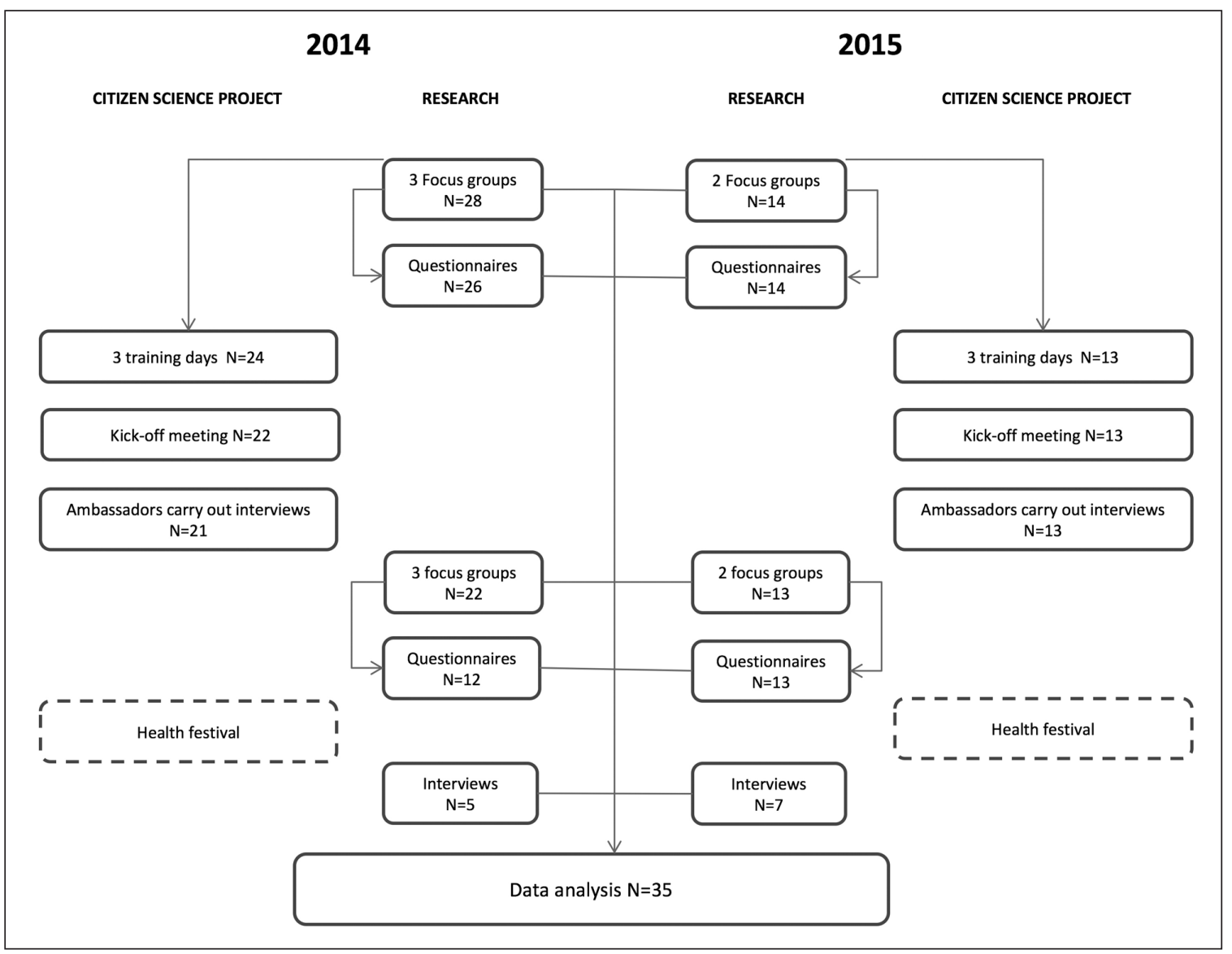

Figure 1: Project overview. Items in the left and right columns are citizen scientists' activities including training; items in the middle column are research activities to study the impacts of their participation as citizen scientists.

being invited. In 2014, those that came forward after the start of the training were placed on a waiting list for the 2015 group. Selection criteria were being a resident of Slotermeer; being engaged in social activities in the neighbourhood; having an interest in community health issues; and being able to speak and understand Dutch on a basic level. Persons who were not selected were invited to participate in other community centre activities such as courses or social groups.

Initially, 42 citizen scientists were recruited. In 2014, six persons dropped out. Four of these decided not to participate immediately after the initial focus groups, which they had attended out of personal interest but not with the aim of participating in the project. Two other citizen scientists dropped out later due to personal 
circumstances. In 2015, one person dropped out for personal reasons, thus 35 citizen scientists remained engaged throughout the project. All were informed, beforehand, that they would receive a financial incentive of $€ 150.00$ for their citizen science work after completion of the second round of focus groups.

Data collection about citizen scientists

Focus groups with both groups of citizen scientists (2014, 2015) were held both before their citizen scientist training and after they had carried out their citizen science task (LDB, MS, WS, KK, AEB). The 45-minute focus groups were held in the community centre, and a focus group protocol was applied. In total 10 focus group with $4-8$ persons were conducted. All focus groups were videorecorded and transcribed verbatim.

The main topic in the focus groups held before the project activities began was how the citizen scientists perceived the health of the neighbourhood. Focus groups were started off by filling out a "thermometer" for the health of the neighbourhood; these scores were then placed on a large wall poster (Figure 2). After this, a discussion took place about health in general and the health of the neighbourhood. The focus groups also served to facilitate the citizen scientists in getting acquainted with the project team and each other.

In the focus groups held after the citizen scientists had carried out their citizen science tasks, two topics were central: The information participants had collected and their personal experiences as citizen scientists. All citizen scientists were also invited as respondents for post-project semi-structured interviews about their experiences as citizen scientists (opportunity sampling) (AVDW, LDB). Average interview duration was 30 minutes, and interviews were recorded and transcribed verbatim. Examples of questions were: "How do you feel about the project Healthy Slotermeer?", "What is your own role in the project?", and "What has the project meant to you as a person?". After the interviews, the citizen scientists received a $€ 10.00$ gift cheque as an acknowledgement.

At focus groups conducted both before and after project activities, the citizen scientists filled out a structured questionnaire. Items included personal data, two visual analogue scales rating personal and neighbourhood health (de Boer et al. 2004), the Chew Three-item Health Literacy (HL) scale, Dutch version (Fransen et al. 2011), and the 13 item Sense Of Coherence (SOC) scale (Dutch version) (Swan et al. 2015). The Chew HL scale measures functional literacy level needed to understand written health information by means of three five-point Likert scale questions. The SOC scale is a validated scale consisting of 13 seven-point Likert scale questions measuring the degree to which a person experiences reality as comprehensible, meaningful, and manageable; a high SOC contributes to health and health behaviour. SOC may increase over the life span, and focused interventions may support this. Therefore, SOC is a key concept in asset approaches in health promotion (Eriksson and Lindström 2005, Nilsson et al. 2010, Super et al. 2014). The SOC-13 scale has been translated and applied in different parts of the world with different groups; a worldwide

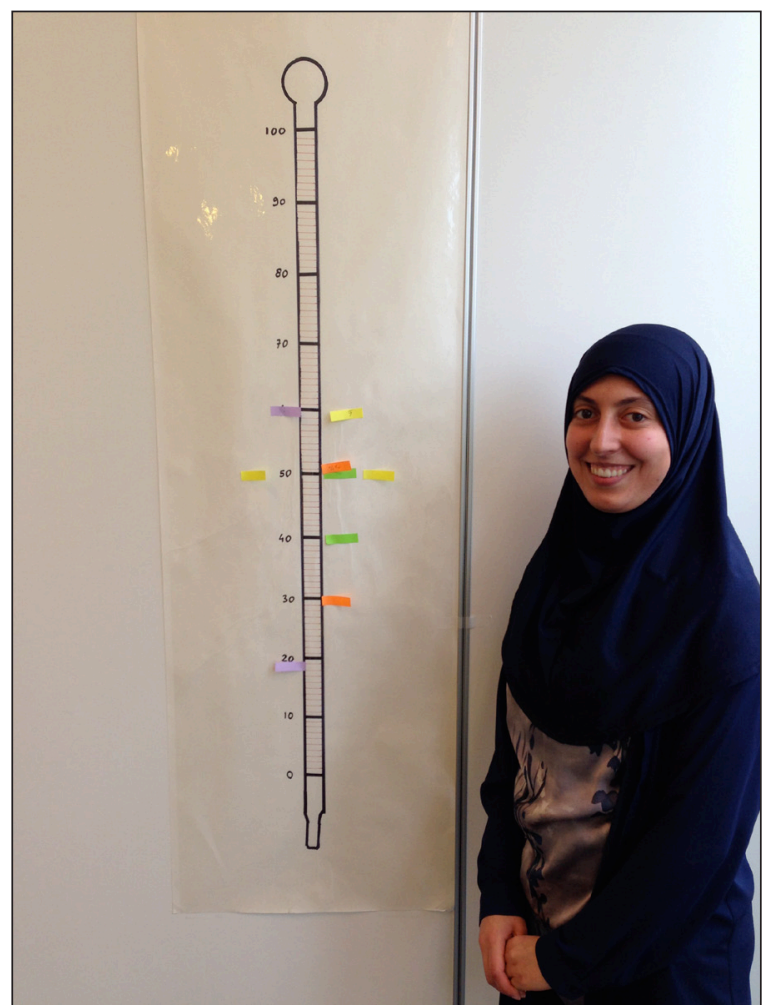

Figure 2: Wall poster displaying citizen scientists' rating of the neighbourhood's health. The person in this photo is a research assistant. Informed consent for use of this photo was obtained.

review looking into the validity of the scale suggests that it is interculturally stable (Eriksson and Lindström 2005) The SOC scale copyright holders granted permission for its use in this study.

Analysis of data about citizen scientists

Analysis of the qualitative data was carried out through descriptive and thematic coding (Tracy 2013). The codebook for descriptive coding was based on a model of benefits for citizen scientists that we presented in an earlier paper (Den Broeder et al. 2016). This model contains four clusters of potential direct impacts of participation in a public-health citizen science project on the citizen scientists (Figure 3). The first cluster refers to increase of health literacy, conceptualised as an asset: "a person's ability to access, understand, and use health information in ways that promote and maintain good health" (Nutbeam 2008: 2076). The second cluster refers to empowerment of citizen scientists to take action on a personal or collective level. The third cluster refers to community building, social capital, social learning, and trust. The fourth cluster refers to change of attitudes, norms and values. These clusters are marked 4, 5, 6 and 7 in the figure. The codebook was tested and refined by pilot coding of two interviews (LL, LdB), then applied to all data, i.e., interview and focus group transcripts (the codebook and code descriptions are presented in Table 3).

Two coders (LDB, LL) carried out coding using MaxQDA software, version 12. Coding outputs were compared; decisions on codes assigned were taken based on consensus. After descriptive coding, output lists per code 


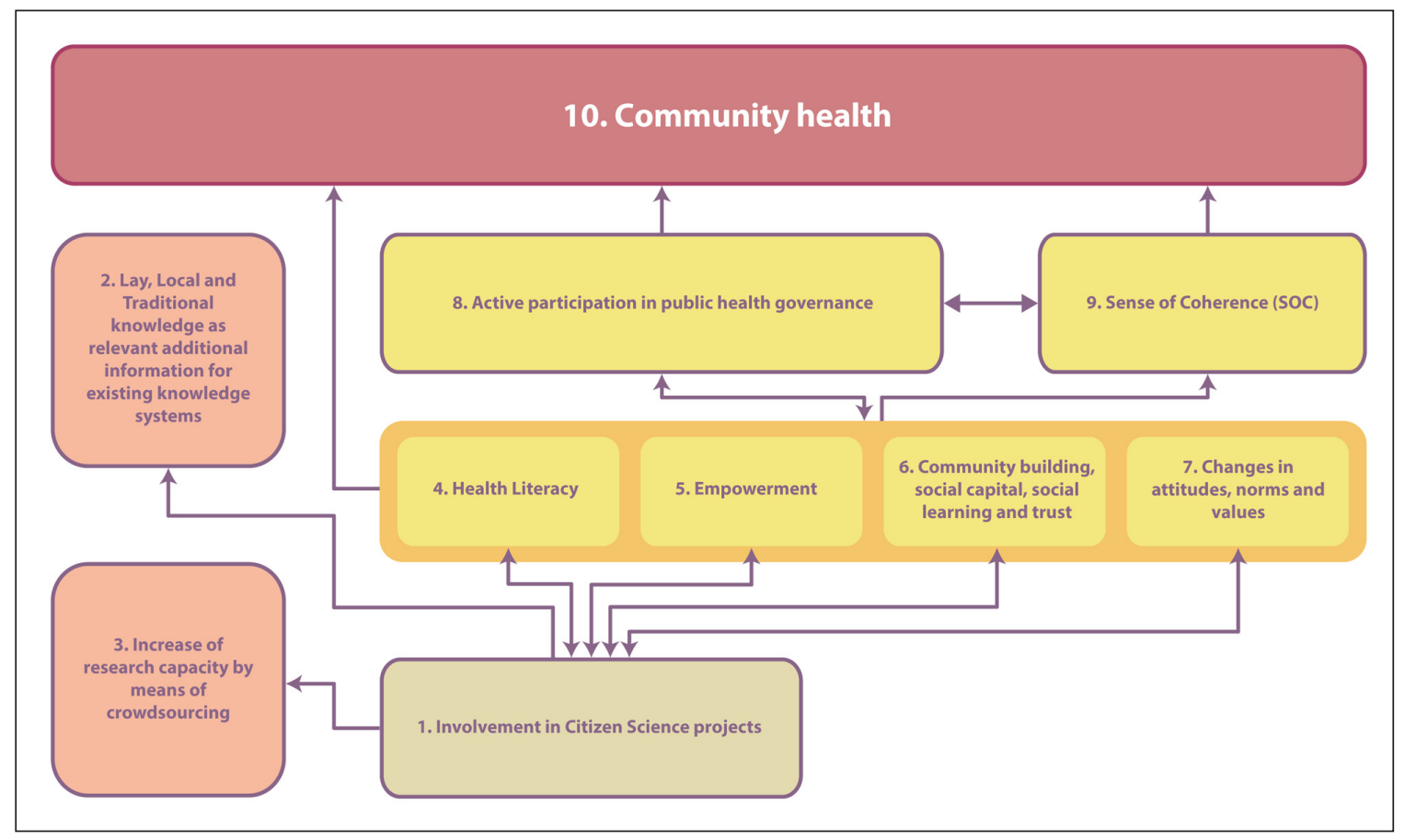

Figure 3: Model of citizen science benefits (Source: Den Broeder et al. 2016).

and per code set were analysed and recurrent themes identified for each code set (thematic analysis). Themes were then clustered across code sets into broader, more generic themes describing citizen scientists' experiences and perceptions (LDB, LL, AW, JS). Coding outputs of focus groups held before training of the citizen scientists were used solely to verify changes of perception (or lack of change) reported by citizen scientists.

We carried out descriptive analysis of the questionnaire data. Responses for the HL scale were scored from 0 to 4 , added, and averaged. An average score $\geq 2$ indicates adequate $\mathrm{HL}$; scores under 2 indicate inadequate $\mathrm{HL}$ (Fransen et al. 2011). Scores on SOC were calculated by adding up the points (1-7) marked for each item. Similar to previous research with this scale in the Netherlands, we rated SOC $\leq 67$ as "low" and SOC $\geq 68$ as "high" (Swan et al. 2016).

The significance of changes in scores before and after participation in the project were analysed by performing paired T-tests on scores for personal and neighbourhood health, HL, and SOC.

\section{Results}

\section{Background of the citizen scientists}

Most citizen scientists were women and most were members of cultural minority groups and/or migrants. Most had a moderate educational level; several nonwestern migrants stated that they had followed a university education in their country of origin. The income level of the citizen scientists was low to moderate - four had paid work while the others were homemakers, unemployed, pensioners, or received social benefits. One was a student. Background data of the citizen scientists is presented in Table 4. Except for gender composition, the citizen scientist groups resemble the neighbourhood's population, with $26 \%$ unemployment (homemakers, in the Netherlands, are not registered as unemployed) and $28 \%$ of the households combining low income with low educational level of the head of household. In Slotermeer, more than $60 \%$ of the inhabitants are of migrant origin, in particular Turkish and Moroccan, and 37 to $41 \%$ of the inhabitants have low literacy levels (Gemeente Amsterdam 2015a).

\section{Focus group and interview results}

All quotes hereafter are Dutch to English translations. As some citizen scientists' mastery of Dutch was basic, the original quotes were not always well formed. These were corrected at translation to improve readability of this paper.

\section{Generic results}

The main reason that the citizen scientists participated was that they were enthusiastic about the theme "health" and felt this was a topic worth working on. They felt the neighbourhood could be improved in that respect and they wished to contribute to that effort:

"Why I joined the project? Because I think it is something good for our neighbourhood. Health is important for us, because the dark spot in Amsterdam is this neighbourhood here, it is Slotermeer."

(interview citizen scientist 30)

Other motivations were that they were keen to meet new people and learn something new. Some citizen scientists with a migrant background saw the project as an opportunity to get in touch with people outside their own cultural group, thereby developing their language skills:

"I thought, this is a good project; I should participate, even though I don't speak Dutch very 


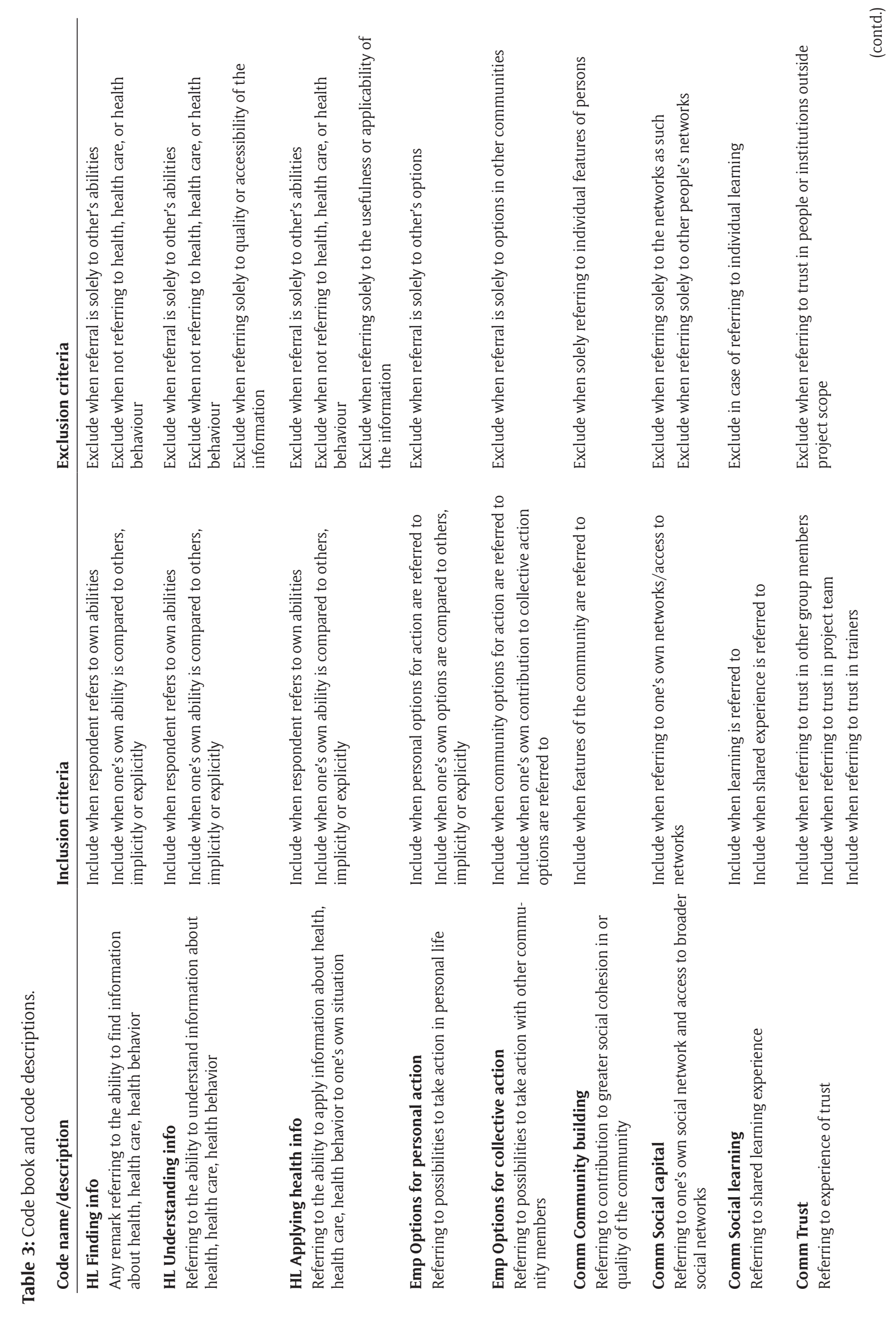




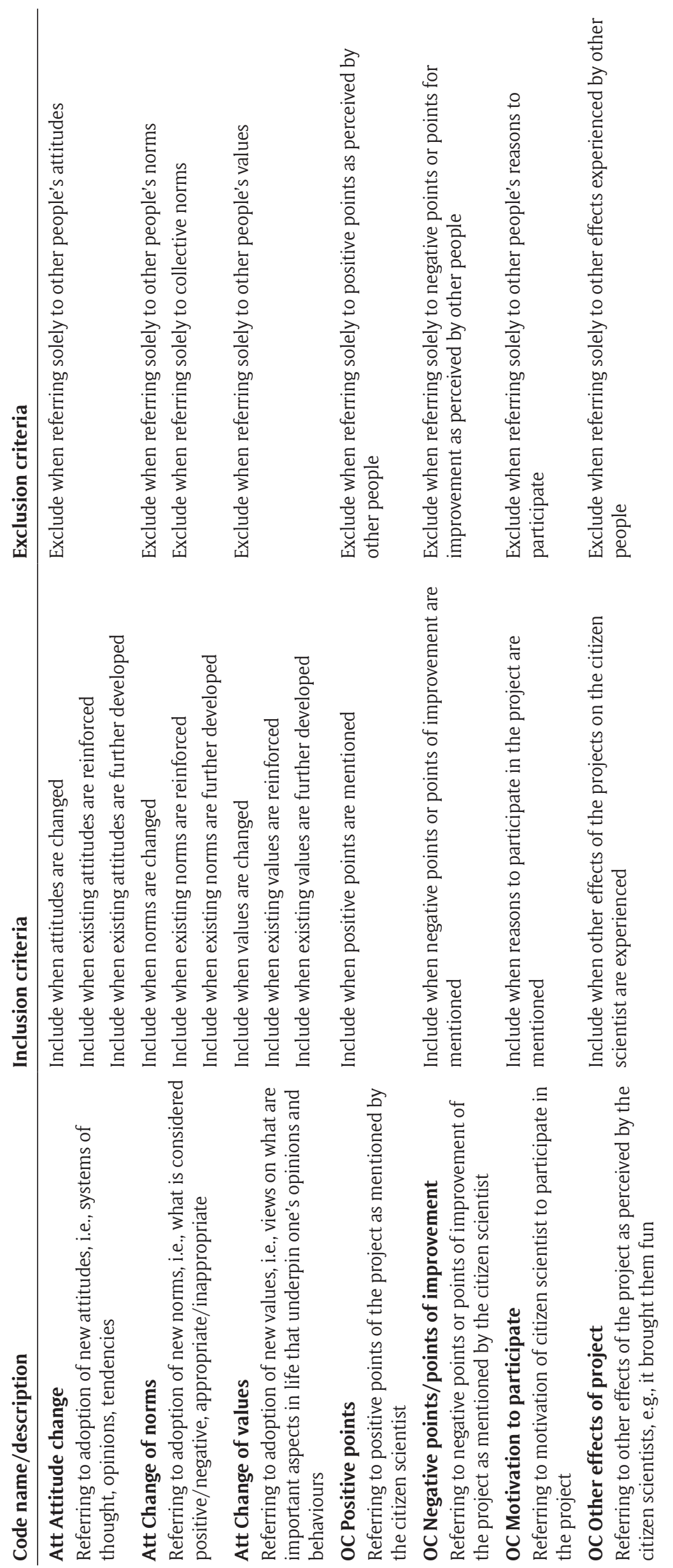


Table 4: Background of citizen scientists.

\begin{tabular}{|c|c|c|c|c|c|}
\hline \multicolumn{6}{|c|}{ Personal characteristics $(\mathrm{N}=35)$} \\
\hline Gender & $\mathbf{N}$ & Age & $\mathbf{N}$ & Country of birth & $\mathbf{N}$ \\
\hline Female & 32 & $21-30$ & 3 & Morocco & 17 \\
\hline \multirow[t]{6}{*}{ Male } & 3 & $31-40$ & 10 & Netherlands & 6 \\
\hline & & $41-50$ & 15 & Turkey & 3 \\
\hline & & $51-60$ & 1 & Egypt & 2 \\
\hline & & $>60$ & 4 & Surinam & 2 \\
\hline & & Unknown & 2 & Other non-western & 2 \\
\hline & & & & Missing & 3 \\
\hline
\end{tabular}

Socioeconomic characteristics $(\mathrm{N}=35)$

\begin{tabular}{lrlrrr}
\hline Education & N & Employment & N & \multicolumn{1}{c}{ Monthly income } \\
\hline None & 1 & Homemaker & 17 & $<1.000$ & 6 \\
Elementary & 3 & Unemployed & 4 & $1.000-1.350$ \\
Secondary/vocational & 17 & Social assistance & 1 & $1.350-1.800$ \\
Higher & 5 & Work (part time) & 3 & $1.800-3.150$ \\
Academic & 6 & Work (full time) & 1 & Won't tell \\
Unknown & 3 & Pensioner & 3 & Don't know \\
& & Student & 1 & Missing & 3 \\
& & Other & 3 &
\end{tabular}

well. But I understand you (the interviewer) for example, and I try to improve my language by this interview, by the communication in Dutch. That is why this contact with others is so important: Otherwise we remain like this forever ... I feel that I need to do something for myself, for my life; not just getting up, watching TV and looking after the children."

(interview citizen scientist 30)

Several citizen scientists mentioned that the financial incentive motivated them. Some also stated that they appreciated being personally acknowledged for contributing to the project. One citizen scientist said she was "sick and tired" of Slotermeer's negative reputation; she was motivated by the opportunity to prove that it was a much better neighbourhood than "outsiders" thought.

Participating in the project was a positive experience for all citizen scientists. They had enjoyed group work during training and felt that learning as a group was more effective than it would have been as an individual. Carrying out interviews was perceived as a new and challenging assignment; they valued this as something very special. They reflected on the project as a new and promising approach to improve the neighbourhood's health:

"I think it is a beautiful way to collect people's ideas and to use that information to do something good for them. At first I thought, 'Healthy Slotermeer,' what's that? It is useless! But after I had joined the project I saw how effective this can be." (interview citizen scientist 22)
A few citizen scientists said that although they liked the project, the practical organisation had not been flawless, in particular regarding timeliness of information about meeting times and places.

Main personal impacts as experienced by citizen scientists Through our thematic analysis of the coded interview and focus group data, we identified an average of 16 themes per code set, with each set relating to one of the dimensions of the model of Citizen Science benefits. These themes were strongly interrelated and a multitude of overlapping aspects could be observed. Clustering the themes across code sets, we could observe six main personal impacts of the project experienced by the citizen scientists (Figure 4).

Understanding the broader determinants of health The citizen scientists reported to have developed a new perception of health as encompassing many other aspects of life, while their initial idea about health was more narrowly focused:

"I had this idea about healthy food, exercise, mental wellbeing. But for many people things like police officers in the streets play a role for health. In that sense I have started to look at health differently, wondering what really makes people healthier. I want to know whether people know what is good for them or what would help them. I don't know that and I am rather curious about it." (interview citizen scientist 7)

The perceptions of health as expressed during the focus groups conducted before their training confirm that 


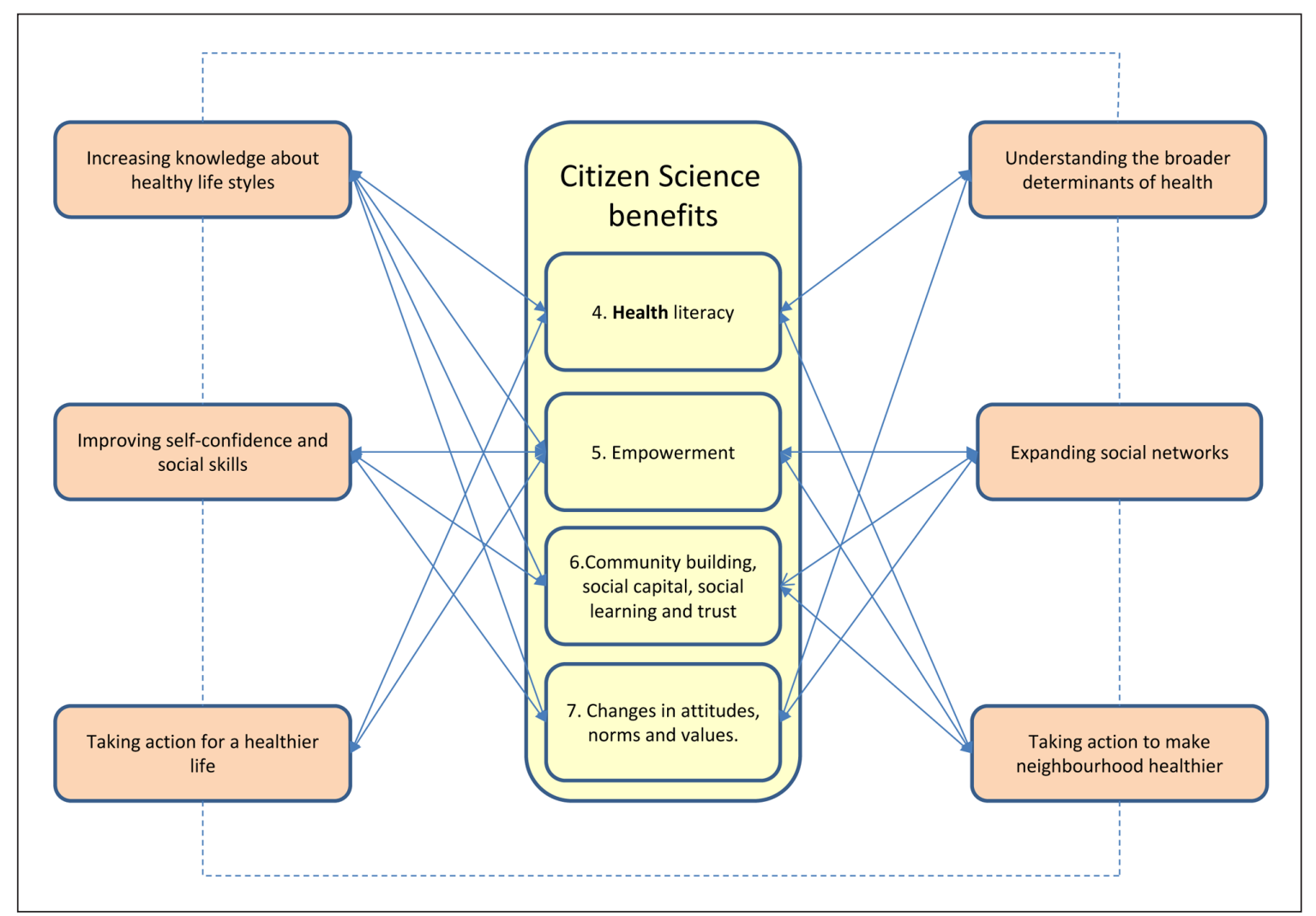

Figure 4: Impacts of the project and citizen science benefits. The numbers relate to the numbers in the model of potential citizen science benefits shown in Figure 3.

a change had occurred. In particular, at that time the citizen scientists had a focus on health as a personal, not collective, issue that depends on one's own behaviour. Several citizen scientists defined health as equal to healthy behaviour: "Today I am healthy because I took a bicycle ride."

The citizen scientists had also adopted a more positive definition of health, instead of focusing on the absence of health problems: "Health is good when it is good, not just when there is nothing wrong."

In addition, during the project, the citizen scientists seem to have developed an understanding of the social determinants of health, perceiving the neighbourhood as an important factor shaping people's health and perceiving their neighbourhood through a "health lens." They have become interested to hear what residents think about the neighbourhood as a healthy or unhealthy place. The citizen scientists report that this gave them new insights about what makes a neighbourhood a healthy place. The importance of living circumstances in the neighbourhood was confirmed to them during the interviews they conducted, sometimes to their own surprise:

"Yeah, they [the residents interviewed, LdB] live here and they had quite some comments about the neighbourhood. For example, they said there is a lot of traffic there. I had never thought about that. You just go to talk to them with a certain vision in mind, with a thought and an expectation. I heard totally different things. That was some kind of special experience."

\section{(focus group 3)}

Increasing knowledge about healthy life styles Most important was the development of health knowledge. The citizen scientists claimed that they learned a lot about health and in particular about healthy life styles. The citizen scientists had developed "health consciousness" through this knowledge, and had started reflecting on their own (and other people's) health habits:

"I was never very much occupied with what I ate. I never thought about anything that I did in terms of how healthy or unhealthy that was. But since the project I am constantly thinking about it. I did that quiz at the health festival and scored terrible results. Then I said to myself: How can you be a Health Ambassador and not know anything about what you eat or drink!". (interview citizen scientist 22)

The citizen scientists said that this learning process was continuing at the time of the interviews/focus groups; they reported the intention to gather more extensive knowledge, either by searching for it by themselves or by subscribing to other courses at the community centre. One example of the latter was a citizen scientist who had enrolled in a course about "healthy development in puberty."

\section{Taking action for a healthier life}

The project seems to have activated citizen scientists to make changes in their personal life. Healthier food patterns were most frequently mentioned, as well 
as taking more physical exercise. Almost all citizen scientists talked about this during interviews and focus groups. They linked this to the information they received during the training, but also to a more generic sense of stronger "health consciousness." They also applied this improved life style to their family and friends:

"I really like it. I myself have changed, because I was not like that before. I take a lot of exercise; my children have all joined sports clubs now. I always cook a healthy dinner. A great many things have changed in my life."

(interview citizen scientist 35)

Other actions mentioned were making their own house healthier, for example by improving the indoor environmental quality, keeping their direct living environment clean by picking up rubbish in the street, investing more in social contacts with neighbours, or taking up new education or training.

Improving self-confidence and social skills

The citizen scientists stated that they had acquired new social competences. They said that, at first, they were insecure when initiating an interview, but were then surprised to experience how easy it was to approach fellow residents, even though some topics were easier to discuss than others. Their self-confidence had grown and they felt that this was due to the project, as they had received training in addressing people and in interview skills. Some reported having gained better mastery of the Dutch language, which made it easier for them to communicate with other people. The citizen scientists felt proud of their work; moreover, they stated that being a "Health Ambassador" provided a certain social status to them:

\footnotetext{
"Well, maybe it gives me a good feeling, too. It is now acceptable for me to speak out in the street: 'Can I talk to you about health?' Even without saying that I am a Health Ambassador. I call it 'ambassador of health issues.' Well, that creates some authority on the spot!".

(interview citizen scientist 14)
}

Several citizen scientists stated that the project gave their personal development a boost; some reported that participation changed their self-image. One citizen scientist held a public presentation about the results of her interviews at the health festival, in the presence of District Council officials, which she experienced as a big step forward:

"I was really someone that could never speak for a group of people. I had been very scared, I had black-outs. But standing there, at that moment, made me think: Hey, I am really proud of myself! After all, I am able to do this!".

(interview citizen scientist 40)
Expanding social networks across cultural boundaries The citizen scientists reported that by participating in the project they extended their personal social networks. They met new people in the group of citizen scientists, and several reported having become friends or keeping connected to the other group members after the project ended, for example, in a WhatsApp group. Several reported that they helped each other in organising health activities in the neighbourhood. The "health festival" was an example about which all spoke with enthusiasm.

Meeting new people in the neighbourhood in general was another effect of the project confirmed by all citizen scientists. In particular, citizen scientists reported that they managed to establish contacts with residents across cultures. This issue was considered of great importance, as they felt that different cultural groups in the neighbourhood do not mix easily; this was one of the most serious problems in Slotermeer, according to the citizen scientists. They had the impression that cultural differences cause a lack of trust between the different groups, and that social cohesion is poor:

"I find it striking, and important, although it is no real news, that everyone here [in Slotermeer, LdB] wants more contact with one another ... Somehow it doesn't work out well, while everyone wants it! All the people I interviewed said the same: They want more contact. If everyone wants it, then why doesn't it happen?".

(focus group 3)

The citizen scientists expressed the wish that the Slotermeer residents would learn to understand, respect, and value each other's culture so that the social quality of the neighbourhood could be improved. They hoped the project could contribute to that; although it could only be a small contribution it might set off a larger movement. The fact that, as citizen scientists, they managed to establish cross-cultural contacts in the course of the project was important to them. They identified two important factors that helped them to accomplish this. First, the citizen scientists mention learning experiences during training sessions that were helpful: They had learned to listen to others without judging and to respect other people's opinions and views. They also experienced a feeling of being respected themselves:

"And you are being listened to. You give each other space to talk. That is what I experienced. Like citizen scientist X said: At first, she did not dare to speak, out of fear to make mistakes in the Dutch language, but now she knows she won't be laughed at" [citizen scientist's name removed for privacy, LdB].

(focus group 5)

This was experienced both within the citizen scientists' group and when interviewing fellow residents. Citizen scientists reported having developed a better understanding and appreciation for people with different 
cultural backgrounds. They often felt surprised by what they saw and heard. One citizen scientist of Dutch origin, for example, reported how her view changed regarding the group members with a Moroccan background:

"I did notice how strong those Ambassadors really are. They are truly powerful women; I was surprised! I find this very positive."

(interview citizen scientist 11)

The second factor that the citizen scientists considered important for their successful cross-cultural contacts was the usefulness of "health" as an inspiring topic for conversation. According to the citizen scientists, "health" was perceived as something everyone can relate to, that no one opposes, and that is relevant for all residents in the neighbourhood. The citizen scientists reported that everyone was eager to discuss health, and that they had surprising and interesting conversations about the topic. Discussing health provided the citizen scientists with a sense of recognition, because the residents they interviewed came up with concerns and views that resembled their own.

Talking about health seems to have created a common interest and thus a reason for people to relate to one another:

"I think choosing health as a topic is great. It is a joint issue. You can look at health from an Islamic or Turkish perspective. But the core of health is that it is human. It is always positive to work on an issue like that; something that just everyone experiences."

(interview citizen scientist 22)

\section{Taking action to make the neighbourhood healthier}

The citizen scientists report they have taken action or plan to do so, to enhance the neighbourhood's health. They base their actions on what they learnt during the training, but also on information gathered when interviewing fellow residents. They discovered, for example, that many residents do not know how to access information about health care and about opportunities for financial support. They report having taken action to improve accessibility of this information.

Several citizen scientists were triggered by resident accounts of the poorstate of housing in the neighbourhood, in particular regarding indoor environments. One citizen scientist collected photos to illustrate this, showing mould on walls and ceilings:

"I would like to talk about the neighbourhood's houses, because I saw photos that are just shocking. I thought my own house was bad, but then the neighbours sent all those photos. I was interested: "how do you live?" Because people sometimes say they live in a dirty place, and some exaggerate the problems. But when I saw those photos I thought: 'this is terrible, how can your children sleep in there?' You just hear that $50 \%$ of those children have asthma!".

(focus group 4)
Their response was attempting to make an inventory of the problems, and pass this information to the housing corporation or the municipality. Several citizen scientists also helped individual families to get the housing corporation to improve the state of their dwelling, for example by making phone calls on behalf of those families.

They also wish to promote healthy lifestyles for their fellow residents. This was one of the reasons to develop and carry out a health festival. However, several said that more was needed. They asked for more training to become lay health extension workers and to run workshops about healthy living. While citizen scientists saw a clear role for themselves, they also called for collective action as a requirement for a healthier neighbourhood. They perceived small, temporary projects as ineffective; arguing that a broader and continuing movement is needed. Although some of them felt that they had already contributed sufficiently by participating in the project, most citizen scientists suggested that they could play a role in setting this up:

"It should not be like this: 'I have a nice little initiative for 10 people.' Then it all stops again. No, it should be broader and it should be linked to those places we call our community centres, to make it easier. But yeah, you would also need a core group of active and engaged residents."

(focus group 3)

Their expectations regarding their ability to improve the neighbourhood's health was not fully optimistic. The citizen scientists reported that residents have lost confidence in local policies or local professionals because of unkept promises. They also reported that many residents had asked them what would happen next, and that they had felt they could not provide an appropriate answer:

"When you talk to those people ... I felt, like, let me say it like this, like my hands were just tied. Because you can't do anything, you really can't do anything at all. If we had been able to do something, we would have. But we weren't."

(focus group 4)

Like their fellow residents, they expressed a sense of powerlessness to accomplish real change. Some reported having developed a less positive vision of their neighbourhood than before the project due to these experiences. One example is the local food environment, which was considered very unhealthy, with an overwhelming supply of fast food and soft drinks. The citizen scientists felt that this problem was something they could not help solve.

\section{Questionnaire results}

Not all citizen scientists completed both questionnaires due to printing problems at the second round of focus groups with the citizen scientists enrolled in 2014. Moreover, many citizen scientists encountered difficulties in filling out the questionnaires, in particular for the SOC-13 items. They experienced the questions as 
complicated and difficult to interpret. However, for those citizen scientists who filled out both questionnaires or parts of them, we compared scores before and after the project. An overview of scores and of the comparisons is shown in Table 5.

At the start of their participation in the project, the citizen scientists rated their own health and the health of the neighbourhood by an average of, respectively, 6.77 and 5.20 on a 10-point scale. At the second measurement, after their participation in the project, these averages were 6.19 and 5.28. A paired comparison of scores before and after the project, i.e., comparing scores at first and second measurement per citizen scientist, showed that the changes were not statistically significant.

The calculated HL score at the start of their participation was "inadequate" for 8 out of 30 citizen scientists. These persons were all migrants with a non-western country of origin, although all but one had been living in the Netherlands for 10 years or longer. After participation, scores were inadequate for 2 out of 20 citizen scientists. Comparing scores per citizen scientist showed an average increase of HL scores by 0.5 . This increase is statistically significant; paired one-tailed T-test yielded a P-value of 0.0045 .

The SOC at the start of participation was "high" for 11 citizen scientists who filled out the SOC scale and "low" for 13 citizen scientists. After participation, of those who filled out the SOC scale, 7 citizen scientists scored "high" and 14 "low." Paired comparison of the calculated SOC scores showed that the changes were not statistically significant.

\section{Discussion and conclusions}

The aims of the Slotermeer project were twofold: To develop knowledge that could serve as input for local policy development, and to enhance the citizen scientists' personal resources to actively engage in improving the community's health. This paper focused on describing the impacts of the project on the citizen scientists.

\section{Discussion of main results}

Our analysis of the qualitative data showed a number of distinct, but closely related, effects of the project on the citizen scientists as shown in Figure 4. First, the citizen scientists changed their views on health and acquired an understanding of the broader determinants of health. Second, they increased knowledge about healthy lifestyles and reflected on these in relation to their personal habits. This materialised in the third impact: Taking action for a healthier life. Fourth, the citizen scientists reported having developed new social competences; related to this, they reported improved self-confidence and social skills. Fifth, the citizen scientists expanded their social networks across cultural boundaries. The sixth reported impact was that the project had functioned as a trigger to take action for a healthier neighbourhood.

The quantitative data confirmed these findings. We found no significant changes in how citizen scientists

Table 5: Scores for personal/neighbourhood health, Health Literacy, and Sense of Coherence. Paired comparisons, i.e., measurements on the same person before and after the project, have been made for those citizen scientists who filled out complete (sub)scales in both questionnaire rounds.

Rating of personal health (scale $0-10)$

Av.

Av.

\begin{tabular}{lllll}
\hline $\begin{array}{l}\text { Average personal health rating before }(\mathrm{N}=30) \text { and after } \\
\text { project }(\mathrm{N}=23)\end{array}$ & Before & 6.77 & After & 6.19 \\
$\begin{array}{l}\text { Paired comparison average personal health rating before } \\
\text { Before }\end{array}$ & Befor & 6.67 & After & $6.24(\mathrm{P}=0.2161)$
\end{tabular}
and after project $(\mathrm{N}=20)$

Rating of neighbourhood health (scale 0-10)

Av.

Paired comparison average neighbourhood health rating Before before and after project $(\mathrm{N}=17)$
Average neighbourhood health rating before project $(\mathrm{N}=30)$ and after project $(\mathrm{N}=23)$

Before

Adequate/inadequate $\boldsymbol{H L}$ (score range $\mathrm{O}-4 ; \geq 2$ adequate)
HL (in)adequacy before project $(N=30)$

$H L$ (in)adequacy after project $(N=20)$

Paired comparison HL scores (in)adequacy $(N=17)$

$H L$ (in)adequacy before project

$H L$ (in)adequacy after project

Paired comparison average HL scores $(N=17)$

SOC scores (range 13-91, $\geq 68$ "high", $\leq 67$ "low")
SOC after project $(\mathrm{N}=21)$

Paired comparison high/low SOC before - after $(\mathrm{N}=15)$

SOC before project

SOC after project

Paired comparison SOC scores before - after $(\mathrm{N}=15)$

\section{Adequate}

Adequate

Adequate

Adequate

Before

$\mathrm{N}$
High

High

High

Before

5.20

5.29

$5.35(\mathrm{P}=0,4270)$

Av.

5.28

\begin{tabular}{|c|c|c|}
\hline 22 & Inadequate & 8 \\
\hline 18 & Inadequate & 2 \\
\hline$N$ & & $N$ \\
\hline 14 & Inadequate & 3 \\
\hline 17 & Inadequate & 0 \\
\hline$A v$. & & $A v$ \\
\hline 2.63 & After & $3.14(P=0.0045)$ \\
\hline $\mathrm{N}$ & & N \\
\hline 11 & Low & 13 \\
\hline 7 & Low & 14 \\
\hline $\mathrm{N}$ & & $\mathrm{N}$ \\
\hline 7 & low & 8 \\
\hline 5 & Low & 10 \\
\hline Av. & & Av. \\
\hline 63.21 & After & $63.28(\mathrm{P}=0.4884)$ \\
\hline
\end{tabular}


rated personal health; this would have been surprising as participation did not last very long and health status, including self-reported health, does not change overnight. The lack of change in the citizen scientists' rating of neighbourhood health before and after their participation in the project was equally unsurprising. The qualitative data show that, on one hand, the citizen scientists came across problems such as poor housing and loneliness, while on the other hand they identified unexpected positive neighbourhood aspects such as attractive greenery and effective public transport. We suppose that these have balanced each other out.

An interesting finding was that the increase in knowledge about and understanding of health issues was reflected in increase of (measured) HL. This also links up to the observation of some citizen scientists that the project helped to improve their level of understanding of the Dutch language.

SOC scores appear to be in line with data collected with this scale in a study of 781 Dutch persons of 18 years and older, which showed high SOC for 386 persons and low SOC for 395 persons (Swan et al. 2016). No significant change of SOC scores occurred. Although other studies have demonstrated that an increase of SOC scores is possible, this requires intensive interventions focused on empowerment and development of reflection capabilities (Super et al. 2015, Kähönen et al. 2012, Vastamäki et al. 2009). The "Healthy Slotermeer" project probably lacked that high degree of intensiveness.

Of course, SOC scores of the citizen scientists must be interpreted with caution as they experienced the questions in the SOC scale as complicated and therefore may have misunderstood some questions. Other Dutch researchers came across similar problems in measuring SOC of people with a low educational level (Herens 2016), but at present there are no validated alternatives that are better suited to similar target groups.

\section{Citizen science and health promotion}

Two things in particular stand out from the results: The contribution of this project to intercultural exchange between the citizen scientists and other residents and the activation of the citizen scientists for their own and the neighbourhood's health. The intercultural exchange, substantiated in the citizen scientists' observation that "health" is a theme that has the potential to join people with different backgrounds, is highly relevant in relation to the setting of the project: A neighbourhood that is strongly divided and where cultural groups do not mix. The citizen scientists' curiosity, and their willingness to listen to different points of view, may very well have played a role in bringing about intercultural contacts. Citizen science has been reported to increase social capital and social cohesion in environmental monitoring (Conrad and Hilchey 2011, Jones et al. 2006, Whitelaw et al. 2003). Our case shows that this might be true not only for monitoring focused on health-relevant environmental factors but also for other types of public health citizen science.

The empowerment and activation of the citizen scientists was part of the project's focus from the beginning. They made their own decisions on how, where, and whom they would interview. Moreover, they presented findings to the community and the District Council and took action to help address problems identified through their research work. The fact that the project was led by community workers, instead of by the researchers, has been meaningful to support the self-organisation of residents in the framework of this project and afterwards.

As described above, learning occurred throughout the project and the citizen scientists reported that they changed lifestyle behaviours or intended to do so. Moreover, they took action to make their neighbourhood a healthier place. As such, it seems that the project has functioned as a health promotion intervention. Indeed, there are linkages between empowerment, social capital, and community health (Wagemakers et al. 2010). Participatory or community approaches are a key element of health promotion, and the reasons why the citizen scientists liked to be part of the project resemble four important motivations for participation identified in effective community health promotion projects: Action that serves a tangible purpose; opportunities for selfdevelopment; recognition and status as a role model; and meaningful relationships (Fienieg et al. 2012). The freedom of the citizen scientists to decide how exactly they would carry out their research work instead of following prescribed procedures - although some might considered it a "threat" to the scientific quality of the data collected - may have enhanced their feeling of ownership of the project.

The project also demonstrates that public health citizen science can very well be put to practice with citizen scientists who do not have high educational levels or good reading and writing skills. As such, this project links up with similar experiences in other work fields (e.g., Bonney et al. 2014, Braschler 2009).

\section{Strengths and weaknesses of this study}

The impacts of the Healthy Slotermeer project were studied on the citizen scientists using the "benefits of citizen science" model. This was a strong point of the project, as the model proved useful to analyse the data collected and identify specific impacts of participation. Moreover, the model helped to provide an overview of the interrelatedness of different aspects. For example, using new knowledge about health to change one's lifestyles can be considered an increase in health literacy, but also as empowerment while increasing options for effective action to improve one's own life. Similarly, improved social capital became apparent in the joint actions of the citizen scientists, some of which can further support social cohesion. An example of this was the organisation of the Health Festival by the citizen scientists.

Another strong point is the combination of different qualitative and quantitative methods to evaluate the impacts of participation on the citizen scientists. This combination made it possible to obtain a richer and more in-depth image of these impacts.

A weakness of this study is that it relies mostly on selfreported impacts: Citizen scientists may have provided socially desirable answers. Other possibilities to study impacts of this project could have been to interview local 
professionals or to count the number of actions taken by citizen scientists. However, listening to the voices of residents that are seldom heard was core to this project. Therefore, we believe that it was appropriate to take their personal experiences as a starting point when evaluating the project's impacts. The use of different techniques to tap these experiences combining focus groups, interviews, and questionnaires provided us with the opportunity to gain deeper insight into these experiences.

\section{Lessons learnt and further steps}

We have shown that public health citizen science may not only help to collect local information, but also can be a good strategy for community based health promotion. The development of residents' skills and the engagement of the community in the development of local strategies to create a social and physical environment that supports health and healthy behaviour are essential elements of the Ottawa Charter's strategies for health promotion. Moreover, the approach seems to benefit citizen scientists with low educational levels. The methods applied, including the training and support of citizen scientists, need to be further developed and evaluated with similar groups and in similar places, adding to the body of knowledge about impacts on citizen scientists.

In this project, first steps were taken to build a partnership between the citizen scientists and the researchers. However, although the citizen scientists did make some decisions regarding their research activities autonomously, much more could be done, for example by means of co-creation in the early design of future research projects. A more equal partnership, with space to discuss and, occasionally, disagree, may enhance beneficial effects both on the research as well as on those participating, both for researchers and citizen scientists (Jagosh et al. 2012, Horowitz et al. 2009).

Moreover, the health promoting potential of public health citizen science projects, like all health promotion, can be meaningful only if embedded in broader, longer lasting strategies (Jackson et al. 2006). Indeed, shortlived projects without follow-up or implementation of their recommendations may have the adverse effects of disappointing and discouraging the groups engaged.

The citizen scientists in this project showed a concern precisely about such a possible lack of follow-up. We recommend therefore that public health citizen science should not be restricted to projects with short duration, but rather should pursue long-term engagement, including activities explicitly addressing citizen scientists' needs for strengthened advocacy skills. In the case described in this paper, for example, we would recommend that the project be linked with the District Development Strategy, which is adapted every four years and provides the background for the annual District Plans. In this way the beneficial impacts of public health citizen science projects on disadvantaged communities could be sustained and enhanced.

\section{Ethics and consent}

All persons included in this study were informed about the aims of the study. Informed consent was obtained for each focus group (all participants), each questionnaire, and each interview. Consent was given orally and was recorded for reasons of varying literacy levels of the participants. Ethics Committee approval was not applicable for this study. The code of conduct for scientific research of the National Institute for Public Health and the Environment, which is based on the Netherlands Code of Conduct for Academic Practice, was adhered to. See: http://www.vsnu. $\mathrm{nl} /$ files/documenten/Domeinen/Onderzoek/The\%20 Netherlands\%20Code $\% 20$ of\%20Conduct $\% 20$ for $\% 20$ Academic\%20Practice $\% 202004 \% 20 \% 28$ version $\% 20$ 2014\%29.pdf.

\section{Acknowledgements}

We are thankful to Age Niels Holstein and Marianne Mahieu of the District Council of Amsterdam Nieuw-West for their support throughout the project. We would like to thank Nikkie Post and Simone de Bruin of the National Institute for Public Health and the Environment for their critical comments on earlier versions of this paper. Most of all, we are indebted to the citizen scientists, the Health Ambassadors of Slotermeer, who kindly agreed to contribute to this study.

\section{Funding Information}

This project was made possible by a grant of the District Council of Amsterdam Nieuw-West. Evaluation of the project was enabled by the Strategic Research Programme of the National Institute for Public Health and the Environment in the framework of project S/015026/01 Tools for community based health monitoring and health impact assessment - exploring "citizen science" approaches.

\section{Competing Interests}

The authors have no competing interests to declare.

\section{References}

Bonney, R., Cooper, C.B., Dickinson, J., Kelling, S., Phillips, T., Rosenberg, K. and Shirk, J., 2009. Citizen science: A developing tool for expanding science knowledge and scientific literacy. BioScience, 59(11): 977-984. DOI: https://doi.org/10.1525/bio.2009.59.11.9

Bonney, R., Shirk, J.L., Phillips, T.B., Wiggins, A., Ballard, H.L., Miller-Rushing, A.J. and Parrish, J.K., 2014. Citizen science. Next steps for citizen science. Science, 343(6178): 1436-1437. DOI: https://doi.org/10.1126/ science. 1251554

Braschler, B., 2009. Successfully implementing a citizenscientist approach to insect monitoring in a resourcepoor country. BioScience, 59(2): 103-104. DOI: https:// doi.org/10.1525/bio.2009.59.2.2

Brossard, D., Lewenstein, B. and Bonney, R., 2005. Scientific knowledge and attitude change: The impact of a citizen science project. International Journal of Science Education, 27(9): 1099-1121. DOI: https://doi. org/10.1080/09500690500069483

Brown, P., 1997. Popular epidemiology revisited. Current Sociology, 45(3): 137-156. DOI: https://doi. org/10.1177/001139297045003008

Conrad, C.C. and Hilchey, K.G., 2011. A review of citizen science and community-based environmental monitoring: Issues and opportunities. Environmental 
Monitoring and Assessment, 176(1-4): 273-291. DOI: https://doi.org/10.1007/s10661-010-1582-5

Creswell, J.W., 2009. Research design: Qualitative, quantitative and mixed methods approaches. Los Angeles: Sage Publications, Inc.

Cronje, R., Rohlinger, S., Crall, A. and Newman, G., 2011. Does participation in citizen science improve scientific literacy? A study to compare assessment methods. Applied Environmental Education \& Communication, 10(3): 135-145. DOI: https://doi.org/10.1080/15330 15X.2011.603611

de Boer, A.G.E.M., van Lanschot, J.J.B., Stalmeier, P.F.M., van Sandick, J.W., Hulscher, J.B.F., de Haes, J.C.J.M. and Sprangers, M.A.G., 2004. Is a single-item visual analogue scale as valid, reliable and responsive as multi-item scales in measuring quality of life? Quality of Life Research, 13(2): 311-320. DOI: https://doi. org/10.1023/B:QURE.0000018499.64574.1f

den Broeder, J.M., Pilon, A. and van de Weerd, A., 2015. Gezondheid verbindt! Evaluatie van het project Gezond Slotermeer. Bilthoven: RIVM.

den Broeder, L., Devilee, J., van Oers, H., Schuit, A.J. and Wagemakers, A., 2016. Citizen science for public health. Health Promotion International, daw086. DOI: https://doi.org/10.1093/heapro/daw086

Egan, J., 2004. Skills for sustainable communities. London: Office of the Deputy Prime Minister.

Eriksson, M. and Lindström, B., 2005. Validity of Antonovsky's sense of coherence scale: A systematic review. Journal of Epidemiology and Community Health, 59(6): 460-466. DOI: https://doi.org/10.1136/ jech.2003.018085

Fienieg, B., Nierkens, V., Tonkens, E., Plochg, T. and Stronks, K., 2012. Why play an active role? A qualitative examination of lay citizens' main motives for participation in health promotion. Health Promotion International, 27(3): 416-426. DOI: https://doi. org/10.1093/heapro/dar047

Fischer, F., 2000. Citizens, experts, and the environment: The politics of local knowledge. Durham, London: Duke University Press. DOI: https://doi. org/10.1215/9780822380283

Fransen, M.P., van Schaik, T.M., Twickler, T.B. and Essink-Bot, M.L., 2011. Applicability of internationally available health literacy measures in the Netherlands. Journal of Health Communication, 16(3): 134-149. DOI: https://doi.org/10.1080/10810730.2011.604383

Gemeente Amsterdam. 2015a. Gebiedsanalyse 2015 Geuzenveld/Slotermeer, Stadsdeel Nieuw-West [City District Analysis 2015 Geuzenveld/Slotermeer, City District of Nieuw-West]. Amsterdam: Gemeente Amsterdam.

Gemeente Amsterdam. 2015b. Gebiedsplan GeuzenveldSlotermeer 2016 [District Development Plan 2016 Geuzenveld Slotermeer]. Amsterdam: Gemeente Amsterdam.

Gemeente Amsterdam. 2016. Gebiedsplan 2017 Geuzenveld-Slotermeer [District Development Plan 2017 Geuzenveld-Slotermeer]. Amsterdam: Gemeente Amsterdam.
Gommerman, L. and Monroe, M., 2012. Lessons learned from evaluations of citizen science programs. Gainesville, FL: School of Forest Resources and Conservation, Florida Cooperative Extension Service, Institute of Food and Agricultural Sciences, University of Florida.

Herens, M., 2016. Promoting physical activity in socially vulnerable groups. A mixed method evaluation in multiple community-based physical activity programs. PhD, Wageningen University. DOI: https://doi. org/10.18174/380446

Horowitz, C.R., Robinson, M. and Seifer, S., 2009. Community-based participatory research from the margin to the mainstream: Are researchers prepared? Circulation, 119(19): 2633-2642. DOI: https://doi. org/10.1161/CIRCULATIONAHA.107.729863

Huber, M., Ja, K., Green, L., van der Horst, H., Jadad, A., Kromhout, D., Leonard, B., Lorig, K., Loureiro, M.I., van der Meer, J.W.M., Schnabel, P., Smith, R., van Weel, C. and Smid, H., 2011. How should we define health? BMJ: British Medical Journal (Online), 343: d4163. DOI: https://doi.org/10.1136/bmj.d4163

Israel, B.A., Schulz, A.J., Parker, E.A. and Becker, A.B., 1998. Review of community-based research: assessing partnership approaches to improve public health. Annual Review of Public Health, 19(1): 173-202. DOI: https://doi.org/10.1146/annurev. publhealth.19.1.173

Jackson, S.F., Perkins, F., Khandor, E., Cordwell, L., Hamann, S. and Buasai, S., 2006. Integrated health promotion strategies: A contribution to tackling current and future health challenges. Health Promotion International, 21(1): 75-83. DOI: https:// doi.org/10.1093/heapro/dal054

Jagosh, J., Macaulay, A.C., Pluye, P., Salsberg, J., Bush, P.L., Henderson, J., Sirett, E., Wong, G., Cargo, M., Herbert, C.P., Seifer, S.D., Green, L.W. and Greenhalgh, T., 2012. Uncovering the benefits of participatory research: Implications of a realist review for health research and practice. The Milbank Quarterly, 90(2): 311-346. DOI: https://doi.org/10.1111/j.1468-0009.2012.00665.x

Jones, F.C., Baird, D., Bowman, M., Cameron, G., Craig, B. and Cutler, B., 2006. Performance of Ontario's benthos biomonitoring network: Impacts on participants' social capital, environmental action, and problemsolving ability. Environments, 34(1): 37-53.

Kähönen, K., Näätänen, P., Tolvanen, A. and Salmela-Aro, K., 2012. Development of sense of coherence during two group interventions. Scandinavian Journal of Psychology, 53(6): 523-527. DOI: https://doi.org/10.1111/sjop.12020

Kolb, D.A., 1984. Experiential learning: Experience as the source of learning and development. Englewood Cliffs: Prentice Hall.

Miller, W.R. and Rollnick, S., 2007. Motivational interviewing in health care: Helping patients change behaviour. New York: Guilford Press.

Minkler, M., 2000. Using participatory action research to build healthy communities. Public Health Reports, 115(2-3): 191-197. DOI: https://doi.org/10.1093/ $\mathrm{phr} / 115.2 .191$ 
Minkler, M., Blackwell, A.G., Thompson, M. and Tamir, H., 2003. Community-based participatory research: Implications for public health funding. American Journal of Public Health, 93(8): 1210-1213. DOI: https://doi.org/10.2105/AJPH.93.8.1210

Nilsson, K.W., Leppert, J., Simonsson, B. and Starrin, B., 2010. Sense of coherence and psychological wellbeing: Improvement with age. Journal of Epidemiology and Community Health, 64(4): 347-352. DOI: https:// doi.org/10.1136/jech.2008.081174

Nutbeam, D., 2008. The evolving concept of health literacy. Social Science \& Medicine, 67(12): 2072-2078. DOI: https://doi.org/10.1016/j.socscimed.2008.09.050

RIVM. 2015. Gezondheid verbindt! Uitkomsten van project Gezond Slotermeer (2014) [Health connects! Results of the Healthy Slotermeer project (2014) - Brochure. Bilthoven: RIVM.

RIVM. 2016. Ambassadeurs in actie! Uitkomsten van project Gezond Slotermeer (2015) [Ambassadors in action! Results of the project Healthy Slotermeer (2015) - Brochure]. Bilthoven: RIVM.

Shirk, J.L., Ballard, H.L., Wilderman, C.C., Phillips, T., Wiggins, A., Jordan, R., McCallie, E., Minarchek, M., Lewenstein, B.V., Krasny, M.E. and Bonney, R., 2012. Public participation in scientific research: A framework for deliberate design. Ecology and Society, 17(2): 29. DOI: https://doi.org/10.5751/ES-04705-170229

South, J. and Phillips, G., 2014. Evaluating community engagement as part of the public health system. Journal of Epidemiology and Community Health, 68(7): 692-696. DOI: https://doi.org/10.1136/jech-2013203742

Super, S., Verschuren, W.M.M., Zantinge, E.M., Wagemakers, M.A.E. and Picavet, H.S.J., 2014. A weak sense of coherence is associated with a higher mortality risk. Journal of Epidemiology and Community Health, 68(5): 411-417. DOI: https://doi.org/10.1136/ jech-2013-203085

Super, S., Wagemakers, M.A.E., Picavet, H.S.J., Verkooijen, K.T. and Koelen, M.A., 2015. Strengthening sense of coherence: Opportunities for theory building in health promotion. Health Promotion International, 31(4): 869-878. DOI: https://doi.org/10.1093/ heapro/dav071
Swan, E., Bouwman, L., Hiddink, G.J., Aarts, N. and Koelen, M., 2015. Profiling healthy eaters. Determining factors that predict healthy eating practices among Dutch adults. Appetite, 89(1): 122-130. DOI: https:// doi.org/10.1016/j.appet.2015.02.006

Swan, E., Bouwman, L., Hiddink, G.J., Aarts, N. and Koelen, M., 2016. Individual, social-environmental, and physical-environmental factors that underlie sense of coherence in Dutch adults. Global Health Promotion. DOI: https://doi.org/10.1177/1757975916639870

Tracy, S.J., 2013. Qualitative research methods. Collecting evidence, crafting analysis, communicating impact. Chichester: Wiley-Blackwell.

Vaandrager, L., van den Driessen Mareeuw, F., Naaldenberg, J., Klerkx, L., Mollman, G., de Regt, W. and Zandvliet, J., 2011. De kennisinfrastructuur van de openbare gezondheidszorg. Vorm en functioneren [The knowledge infrastructure of public health care. Organisation and functioning]. Den Haag: ZonMw.

Vastamäki, J., Moser, K. and Paul, K.I., 2009. How stable is sense of coherence? Changes following an intervention for unemployed individuals. Scandinavian Journal of Psychology, 50(2): 161-171. DOI: https://doi. org/10.1111/j.1467-9450.2008.00695.x

Wagemakers, A., Corstjens, R., Koelen, M., Vaandrager, L., van't Riet, H. and Dijkshoorn, H., 2008. Participatory approaches to promote healthy lifestyles among Turkish and Moroccan women in Amsterdam. Global Health Promotion, 15(4): 17-23. DOI: https://doi. org/10.1177/1025382308097694

Wagemakers, A., Vaandrager, L., Koelen, M.A., Saan, H. and Leeuwis, C., 2010. Community health promotion: A framework to facilitate and evaluate supportive social environments for health. Evaluation and Program Planning, 33(4): 428-435. DOI: https://doi. org/10.1016/j.evalprogplan.2009.12.008

Whitelaw, G., Vaughan, H., Craig, B. and Atkinson, D., 2003. Establishing the Canadian Community Monitoring Network. Environmental Monitoring and Assessment, 88(1-3): 409-418. DOI: https://doi. org/10.1023/A:1025545813057

World Health Organization. 1986. The Ottawa Charter for Health Promotion. Ottawa: World Health Organization.

How to cite this article: Den Broeder, L., Lemmens, L., Uysal, S., Kauw, K., Weekenborg, J., Schönenberger, M.,

Klooster-Kwakkelstein, S., Schoenmakers, M., Scharwächter, W., Van de Weerd, A., El Baouchi, S., Schuit, A.J. and Wagemakers, A. 2017 Public Health Citizen Science; Perceived Impacts on Citizen Scientists: A Case Study in a Low-Income Neighbourhood in the Netherlands. Citizen Science: Theory and Practice, 2(1): 7, pp. 1-17, DOI: https://doi.org/10.5334/cstp.89

Submitted: 08 November 2016 Accepted: 23 June 2017 Published: 09 November 2017

Copyright: $\odot 2017$ The Author(s). This is an open-access article distributed under the terms of the Creative Commons Attribution 4.0 International License (CC-BY 4.0), which permits unrestricted use, distribution, and reproduction in any medium, provided the original author and source are credited. See https://creativecommons.org/licenses/by/4.0/.

$\mathrm{u}[\quad$ Citizen Science: Theory and Practice is a peer-reviewed open access journal published by Ubiquity Press. 